\title{
Produção de metabólitos secundários em cultura de células e tecidos de plantas: $O$ exemplo dos gêneros Tabernaemontana e Aspidosperma
}

\author{
Elisângela Fumagali, ${ }^{1}$ Regina Aparecida Correia Gonçalves, ${ }^{1}$ Maria de Fátima Pires Silva \\ Machado, ${ }^{2}$ Gentil José Vidoti, ${ }^{3}$ Arildo José Braz de Oliveira ${ }^{*, 1}$ \\ ${ }^{I}$ Departamento de Farmácia e Farmacologia, Universidade Estadual de Maringá, Campus Universitário, \\ Avenida Colombo, 5790, 87020-900 Maringá-PR, Brasil, \\ ${ }^{2}$ Departamento de Biologia Celular e Genética, Universidade Estadual de Maringá, Avenida Colombo, 5790, \\ 87020-900 Maringá-PR, Brasil, \\ ${ }^{3}$ Departamento de Química, Universidade Estadual de Maringá, Avenida Colombo 5790, \\ 87020-900 Maringá-PR, Brasil
}

\begin{abstract}
RESUMO: Os estudos dos metabólitos secundários de plantas se desenvolveram aceleradamente nos últimos 50 anos. Estes compostos são conhecidos por desempenharem um papel importante na adaptação das plantas aos seus ambientes e também representam uma fonte importante de substâncias farmacologicamente ativas. As técnicas de cultura de células de plantas iniciaramse na década de 1960 como uma possível ferramenta para estudar e produzir os metabólitos secundários de plantas. $\mathrm{O}$ uso de cultura de células de planta para a produção de substâncias de interesse contribuiu grandemente para avanços em diversas áreas da fisiologia e bioquímica vegetal. Diferentes estratégias, usando sistemas de cultura in vitro, foram estudadas com o objetivo de aumentar a produção de metabólitos secundários. As plantas dos gêneros Aspidosperma e Tabernaemontana são importantes fontes de alcalóides indólicos biologicamente ativos, sendo que no Brasil existe um número considerável de espécies destes gêneros. As culturas de células de Aspidosperma e Tabernaemontana foram iniciadas há pelo menos 16 anos, as quais produzem um grande número de alcalóides, o que estimulou o desenvolvimento de diversas técnicas para sua produção, extração e identificação.
\end{abstract}

Unitermos: Metabólitos secundários, alcalóides indólicos, cultura de células de plantas, Apocynaceae, Aspidosperma, Tabernaemontana.

\begin{abstract}
Production of plant secondary metabolites in plant cell and tissue culture: The example of Tabernaemontana and Aspidosperma genera". Studies on plant secondary metabolites have been increasing over the last 50 years. These compounds are known to play a major role in the adaptation of plants to their environment and an important source of active pharmaceuticals. Plant cell culture technologies were introduced at the end of the 1960 s as a possible tool for both studying and producing plant secondary metabolites. Different strategies, using in vitro systems, have been extensively studied with the objective of improving the production of secondary plant compounds. The Aspidosperma and Tabernaemontana genera are an important source of biologically active alkaloids and in Brazil there is a considerable number of species of these genera. About 16 years ago cell cultures of Tabernemontana and Aspidosperma were initiated. These cell cultures did produce a number of alkaloids of pharmaceutical interest that stimulated the development of several techniques to production, extraction and identification.
\end{abstract}

Keywords: Secondary metabolites, indolic alkaloids, plant cell culture, Apocynaceae, Aspidosperma, Tabernaemontana.

\section{INTRODUÇÃO}

A quase duzentos anos a Química e a Biologia moderna vêm descrevendo o papel do metabolismo primário em funções básicas vitais, como por exemplo, na divisão, crescimento celular, respiração, estocagem e reprodução. Por outro lado o conceito de metabolismo secundário em biologia foi descrito por Kossel (1891), que foi o primeiro autor a definir os metabólitos secundários como opostos aos metabólitos primários. Os metabólitos secundários têm sido sumariamente definidos como compostos pouco abundantes, com uma freqüência inferior a $1 \%$ do carbono total, ou pelo fato de sua estocagem ocorrer em órgãos ou células específicos. O desenvolvimento nas técnicas analíticas no século 20 como, por exemplo, os diversos tipos de cromatografia, 
permitiram isolar mais destas moléculas, constituindose como a base para o estabelecimento da disciplina de fitoquímica (Harborne, 1998).

Os produtos secundários têm um papel importante na adaptação das plantas aos seus ambientes; essas moléculas contribuem para que as mesmas possam ter uma boa interação com os diferentes ecossistemas (Aerts et al., 1991; Harborne, 1988). Os produtos secundários aumentam a probabilidade de sobrevivência de uma espécie, pois são responsáveis por diversas atividades biológicas com este fim como, por exemplo, podem atuar como antibióticos, antifúngicos e antivirais para proteger as plantas dos patógenos, e também apresentando atividades antigerminativas ou tóxicas para outras plantas, fitoalexinas. Além disso, alguns destes metabólitos constituem importantes compostos que absorvem a luz ultravioleta evitando que as folhas sejam danificadas (Li et al., 1993).

Os compostos secundários de plantas são usualmente classificados de acordo com a sua rota biossintética (Harbone, 1999). As três famílias de moléculas principais são geralmente consideradas: os compostos fenólicos, terpênicos e esteróides, e os alcalóides. A função dos compostos fenólicos está envolvida com a síntese das ligninas que são comuns a todas as plantas superiores, atrativos aos seres humanos devido ao odor, sabor e coloração agradáveis, mas também para outros animais, os quais são atraídos para polinização ou dispersão de sementes. Além disso, esse grupo de compostos é importante para proteger as plantas contra os raios ultravioleta, insetos, fungos, vírus e bactérias (Croteau et al., 2000). Há inclusive certas espécies vegetais que desenvolveram compostos fenólicos para inibir o crescimento de outras plantas competidoras (ação alelopática). Os alcalóides podem ser definidos como compostos farmacologicamente ativos, contendo um nitrogênio e derivados de aminoácidos (Cordell, 1981). Entretanto os alcalóides não são distribuídos de maneira uniforme no reino vegetal e são mais específicos para alguns gêneros e espécies de plantas. Esta distribuição restrita dos compostos secundários constitui a base da quimiotaxonomia e ecologia química (Harborne, 1988). O papel dos alcalóides nas plantas ainda é uma questão difícil de ser respondida, mas de acordo com Croteau et al. (2000), algumas respostas estão surgindo amparadas nas funções eco-químicas destes compostos. O papel dos alcalóides nas defesas químicas das plantas é sustentado pela grande variedade de efeitos fisiológicos que estes exercem sobre os animais e também por suas atividades antimicrobianas. Vários alcalóides são tóxicos aos insetos e atuam como repelente para herbívoros.

Devido às extensas atividades biológicas dos metabólitos secundários de plantas, estes são utilizados há séculos na medicina popular e nos dias atuais, como medicamentos, cosméticos, matéria-prima para a química fina, ou mais recentemente como nutracêuticos (Yunes \& Chechinel, 2001; Amaral et al., 2006; Funke
\& Melzig, 2006; Biavatti et al., 2007; Barbosa-Filho et al., 2007; Saúde-Guimarães \& Faria, 2007; BarbosaFilho et al., 2008). Estudos recentes estabeleceram que nos países ocidentais, onde a química sintética é a base da indústria farmacêutica, $25 \%$ das moléculas alvo foram originalmente isoladas de plantas (Barreiro, 1991; Viegas Jr et al., 2006). Apesar dos grandes avanços na química sintética, a produção de metabólitos secundários de plantas, por muito tempo, vem sendo feita por cultivo das plantas medicinais. Por outro lado, plantas originárias de biótipos específicos podem ter muitas dificuldades para crescer fora de seus ecossistemas locais. Algumas espécies de plantas comuns não podem ser cultivadas em larga escala devido à sua susceptibilidade a patógenos (ex. antracnose para Hypericum ou Arnica montana). Isto tem conduzido os cientistas e biotecnologistas a considerar as culturas de células, tecidos e órgãos como uma maneira alternativa para produzir os correspondentes metabólitos secundários in vitro.

\section{A cultura de células de plantas}

A produção de metabólitos secundários empregando cultura de células de plantas vem sendo amplamente estudada (Charlet et al., 2000). As plantas que produzem compostos bioativos são frequentemente obtidas a partir de coleta predatória e indiscriminada (Villareal et al., 1997), por estes motivos as pesquisas visando à produção destes metabólitos secundários em cultura são vantajosas tanto do ponto de vista ecológico como econômico. Como um sistema experimental, a cultura de células de plantas fornece uma série de vantagens sobre os estudos com plantas íntegras, incluindo a geração de material necessário para os estudos em torno de um ano, células indiferenciadas, estado de desenvolvimento das células relativamente uniforme, ausência da interferência de microrganismos; e mais importante, o ciclo vegetativo reduzido (Croteau et al., 2000). As culturas de células de plantas podem sintetizar grandes quantidades de metabólitos secundários dentro de um período de cultivo de duas semanas. Isto é muito favorável em relação a produção na planta, para as quais o espaço de tempo para o acúmulo destes metabólitos pode variar de uma estação para plantas anuais ou diversos anos no caso da plantas perianuais, como por exemplo as árvores. Nas culturas de células de plantas as taxas de biossíntese podem ser aumentadas, facilitando grandemente os estudos (Croteau et al., 2000; Santos et al., 2007).

\section{A seleção das plantas}

As principais abordagens em um programa de pesquisa para produção de metabólitos secundários em cultura de plantas estão apresentadas na Figura 3. Na primeira fase dos estudos os farmacognosistas e químicos procuram descobrir os princípios ativos presentes nas 
plantas (Hambúrguer \& Hostettmann, 1991). Uma vez que os compostos de interesse são identificados nos extratos das plantas, a primeira parte do trabalho consiste em reunir uma grande variedade de amostras de diferentes indivíduos da mesma espécie que produzam as substâncias desejadas. Este trabalho permite selecionar plantas hiperprodutoras que apresentam o metabólito secundário de interesse.

\section{O estabelecimento da cultura das linhagens celulares in vitro}

Após a seleção dos indivíduos mais promissores, tem início o trabalho de cultura de células in vitro, com a indução dos calos. Para a obtenção dos calos é necessário determinar o meio de cultura adequado para a inoculação e manutenção destes tecidos. A otimização do meio de cultivo é realizada modificando-se a composição mineral e orgânica com atenção especial para o balanço de reguladores de crescimento (auxina/citocinina) que governam os mecanismos de diferenciação e desdiferenciação celular. Esta é uma etapa empírica, relativamente longa, mas que pode ser facilitada pelo uso de experimentos fatoriais incompletos ou métodos de resposta de superfície (Box, 1954; Barros Neto et al., 1996).

Para um planejamento fatorial é preciso primariamente especificar os níveis em que cada fator será estudado, isto é, os valores dos fatores (concentração de auxinas e citocininas) que serão empregados nos experimentos (Barros Neto et al., 1996). Para estudar o efeito das concentrações de auxina em quatro níveis, por exemplo, 0,5 mg/L, 1,0 mg/L, 2,0 mg/L e 4,0 mg/L, e o efeito das citocininas em três níveis, $0,5 \mathrm{mg} / \mathrm{L}, 1,0$ $\mathrm{mg} / \mathrm{L}, 2,0 \mathrm{mg} / \mathrm{L}$ é necessário um planejamento fatorial que requer a execução de experimentos para todas as combinações possíveis dessas concentrações. Cada um desses experimentos, em que o sistema é submetido a um conjunto de níveis definidos, é um ensaio experimental.

Após a indução dos calos, é necessário um período de subculturas periódicas (transferência de fragmentos dos calos para um meio de cultura novo) para garantir a estabilidade e/ou uniformidade dos tecidos de calos. Isto porque, variações somaclonais geradas in vitro podem ocorrer com relativa freqüência em tecidos de calos (Machado \& Colleti, 1991). Esta variação gerada in vitro pode determinar uma produção de metabólitos secundários frequentemente variável, entre um ciclo e outro dos subcultivos. De acordo com Bourgaud et al. (2001), são necessários vários ciclos de subculturas para que os calos apresentem um crescimento uniforme e possam ser considerados como um agregado de células homogêneas, como se fossem derivados de uma única célula clonada.

\section{Culturas de células em suspensão}

Quando a estabilidade genética é alcançada, é necessário selecionar as diferentes linhagens de calos de acordo com a sua competência celular para garantir uma produção eficiente do metabólito de interesse. Portanto, cada calo deve ser testado separadamente, para avaliar a velocidade de seu crescimento, bem como as concentrações intracelulares e extracelulares do metabólito. Isto permite uma avaliação da produtividade de cada linhagem celular ( $\mathrm{mg}$ do produto $\mathrm{g}^{-1}$ de célula $\operatorname{dia}^{-1}$ ou mg do produto $\mathrm{L}^{-1} \mathrm{dia}^{-1}$ ) para que somente as linhagens mais produtoras sejam empregadas nos estudos de células em suspensão ou biorreatores.

$\mathrm{Na}$ cultura de células em suspensão, quando comparada à cinética de crescimento celular a qual é usualmente uma curva exponencial, a maioria dos metabólitos secundários é produzida durante a fase de platô. Este déficit na produção durante os estágios iniciais pode ser explicado pela alocação de carbono estar distribuída preferencialmente com o metabolismo primário (construção das estruturas celulares e respiração) quando o crescimento é muito ativo. Por outro lado, quando o crescimento cessa, quantidades elevadas de carbono não são mais necessárias para o metabolismo primário e os compostos secundários podem ser sintetizados mais ativamente (Machado et al., 2006).

De acordo com Scott et al. (1981) e Verpoorte \& Maraschin. (2001) as células em suspensão constituem um bom material biológico para estudos sobre rotas biossintéticas. Quando comparado às culturas de calos, as células em suspensão permitem a recuperação de grandes quantidades de células das quais as enzimas podem ser facilmente isoladas.

\section{Seleção de linhagens altamente produtivas}

As culturas de células de plantas representam uma população heterogênea nas quais as características fisiológicas das células são individualmente diferentes. Berlin \& Sasse (1985) descrevem alguns critérios que devem ser utilizados na seleção e pesquisa de linhagens celulares com alta capacidade de produção de diversos produtos. A identificação de linhagens celulares com alta produtividade tem sido feita através do cultivo de protoplastos, mas um dos métodos mais promissores é a seleção de pequenos agregados celulares (Verpoorte \& Maraschin, 2001). No caso do cultivo de protoplastos as dificuldades associadas ao isolamento e cultivo das células isoladas limitam a aplicação deste método, enquanto que a seleção de agregados celulares, a despeito de ser um processo laborioso, é de mais fácil execução e apresenta maiores índices de sucesso (Yamada \& Fugita, 1983). Um exemplo do uso de agregados celulares de Coptis japonica permitiu obter uma linhagem celular, a qual cresceu mais rapidamente e produziu altas quantidades do alcalóide berberina (Yamada \& Sato, 1981). Estudos empregando agentes de seleção como 
o 5-metil-triptofano, o glifosato e a biotina foram feitos com o objetivo de selecionar linhagens celulares altamente produtivas (Collin, 2001).

\section{Aumento da produtividade em cultura de células de plantas}

Muitas estratégias podem ser utilizadas para induzir ou aumentar a produção de metabólitos secundários (Shepherd, 1995). Uma das maneiras mais efetivas, em muitos casos, é a adição de compostos precursores ou intermediários ao meio de cultivo celular (Silvestrini et al., 2002). Outra estratégia interessante é a elicitação que representa usualmente uma das técnicas de maior sucesso, esta técnica consiste na aplicação de um estresse químico ou físico nas células em suspensão para induzir a produção de metabólitos secundários que frequentemente não são produzidos. Isto é feito geralmente com elicitores bióticos (quitosanas, micélios de fungos patogênicos, vários extratos de proteínas) ou fatores abióticos (temperatura, luz, metais pesados, $\mathrm{pH}$, etc.). Os elicitores normalmente atuam reduzindo o tempo necessário para se atingir altas concentrações do produto de interesse. $\mathrm{O}$ uso de diferentes tipos de elicitores para induzir e aumentar a produção de metabólitos secundários de interesse comercial tem sido descrito em diversos trabalhos (Wang \& Zhong, 2002; Dong \& Zhong, 2001; Hu et al., 2001; Lee \& Shuler, 2000).

\section{O aumento de escala e o uso de biorreatores}

Os estudos em biorreatores representam à última etapa que leva a uma possível produção de um metabólito secundário por cultura de células de plantas. Esta é uma fase importante, pois os problemas aumentam quando se tenta transpor o trabalho realizado em frasco de cultivo para uma escala maior. Um dos aspectos a ressaltar é que o crescimento é modificado consideravelmente quando as células são cultivadas em grandes tanques e a produção de biomassa se mantem como um ponto crítico para produtividade em biorreator. Isto ocorre devido principalmente a limitações de transferência de massa do oxigênio (Hulst et al., 1985), de nutrientes (Jones \& Veliky, 1981), bem como devido aos sistemas de cultura não homogêneos que causam a sedimentação e morte celular. Estudos de Steward et al. (1999) confirmaram a baixa porcentagem de viabilidade celular, em torno de $50 \%$, normalmente presente nos sistemas líquidos, exceto nos primeiros dias das culturas. Outra forte limitação ao crescimento é decorrente da alta sensibilidade da célula vegetal ao estresse provocado devido ao atrito entre as células; este é responsável por grande parte da morte celular. Esta lise é uma conseqüência da agitação do meio de cultura. Esta lise tende aumentar quando as células estão mais velhas, pois nessa fase elas estão maiores. Muitos estudos descrevem processos de agitação alternativos os quais foram desenvolvidos para reduzir esta lise como os reatores por dispersão de ar ou geradores de bolhas ao invés das tradicionais hélices propelentes (Dixon \& Gonzales, 1994). Isto permite que a produção de biomassa aumente até um nível compatível com o processo. Após uma etapa bem sucedida de otimização da produção de biomassa nos biorreatores, a cultura de células de planta deve passar por um processo de adaptação de maneira a alcançar uma boa produção dos metabólitos de interesse.

\section{Análise e identificação dos metabólitos secundários produzidos em cultura de plantas}

Existem diversos métodos para a análise e identificação de metabólitos secundários conhecidos produzidos em culturas de plantas. A análise de misturas complexas é usualmente feita por cromatografia em camada delgada (CCD), por comparação com os valores de fator de retenção (Rf) de substâncias conhecidas em diferentes sistemas eluentes e pela sua reatividade frente a diferentes produtos cromogênicos (Van Beek \& Van Gessel, 1988). A CCD ainda permanece como um dos métodos preferidos para análise qualitativa de compostos conhecidos, pois não requer equipamentos sofisticados ou uma preparação laboriosa de amostra.

Para análise quantitativa, sistemas de cromatografia líquida de alta eficiência (CLAE) acoplada com detector de UV-VIS é a técnica mais utilizada (Theodorides et al., 1998; Giroud et al., 1991). Os trabalhos mais recentes estão empregando a CLAE acoplada a espectrometria de massas na análise qualitativa e quantitativa (Lépine et al., 2002).

A cromatografia a gás capilar (CG) também é bastante utilizada (Dagnino et al., 1991) e uma importante característica da CG é o seu grande poder de detecção e separação dos compostos. A utilização da CG acoplada a espectrometria de massas (CG/EM) permite a identificação dos compostos presentes em quantidades mínimas, mesmo em misturas complexas (Zocoller et al., 2005).

A cromatografia de fluído supercrítico (CFS) é um outro método empregado, que utiliza colunas empacotadas similares às de CLAE ou colunas capilares semelhantes às usadas em CG/EM (Choi et al., 2002). A CFS tem um grande potencial de aplicabilidade em razão de sua grande resolução e alta estabilidade dos compostos sob as condições de uso.

A eletroforese capilar (EC) é uma técnica que vem sendo utilizada com relativo sucesso, pois apresenta grande sensibilidade associada à alta resolução. A eletroforese capilar é aplicável na determinação de uma grande variedade de amostras, incluindo vitaminas hidro-lipossolúveis, aminoácidos, íons inorgânicos, ácidos orgânicos, fármacos, catecolaminas, substâncias quirais, proteínas, peptídeos e muitos outros (Guttman 
et al., 2004; Mazak et al., 2000). Uma característica que difere a EC das outras técnicas é a sua capacidade única para separar macromoléculas carregadas eletricamente de interesse tanto em indústrias de biotecnologia quanto em pesquisas biológicas. Outro aspecto importante é a possibilidade de acoplamento da EC a espectrometria de massas utilizando-se técnicas de ionização suaves como eletrospray, termospray e ionização a pressão atmosférica (Guttman et al., 2004, Mazak et al., 2000).

\section{Cultura de células de plantas do gênero Tabernaemontana}

A taxonomia da família Apocynaceae é bastante complexa, havendo dificuldades quanto a sua classificação e nomenclatura, porque existe um número grande de espécies sinônimas. Existe um total de 100 espécies, das quais foram isolados cerca de 300 diferentes alcalóides indólicos (Van Beek et al., 1984).
No Brasil, os gêneros Tabernaemontana e Peschiera são alvos de polêmica, porque ambos os nomes genéricos têm sido utilizados (Weisback et al., 1963).

Várias espécies do gênero Tabernaemontana são utilizadas na medicina popular contra diversos tipos de enfermidades: diarréia, doenças de pele, verrugas, sífilis, hanseníase, câncer e picadas de insetos (Van Beek \& Van Gessel, 1988; Agra et al., 2007 \& 2008).

Os principais constituintes químicos dos metabólitos secundários do gênero Tabernaemontana são alcalóides indólicos. Dentre estes a voacamina (1), voacamidina (2), vobasina (3), voacangina (4), afinisina (5), perivina (6), ibogaína (7), tabernantina (8), coronaridina (9). Segundo Federici et al. (2000) os alcalóides indólicos são uma classe de substâncias com amplo espectro de atividades farmacológicas: analgésica, antiinflamatória, bactericida, estrogênica, estimulante e depressora do sistema nervoso central (Van Beek et al., 1984) e com função hipotensiva e atividade muscular

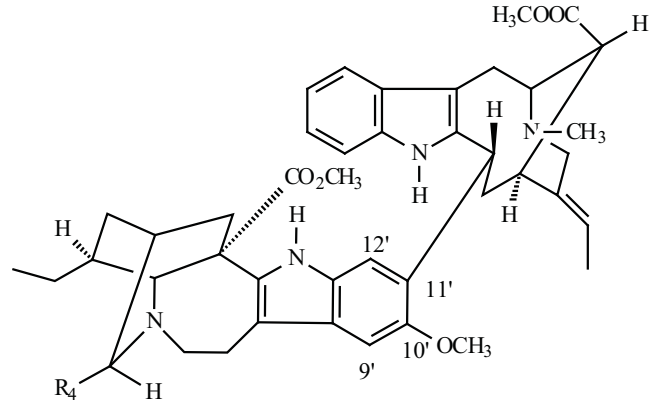

1 voacamina

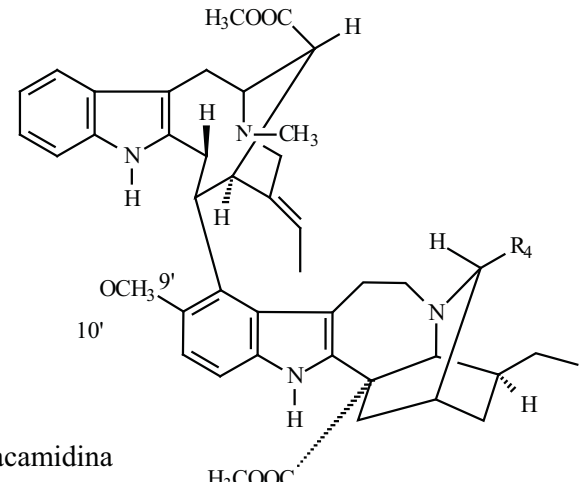

$\mathrm{H}_{3} \mathrm{COOC}$

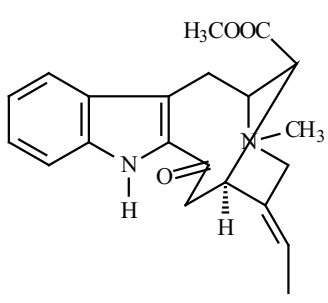

3 vobasina

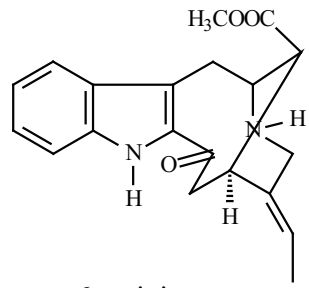

6 perivina

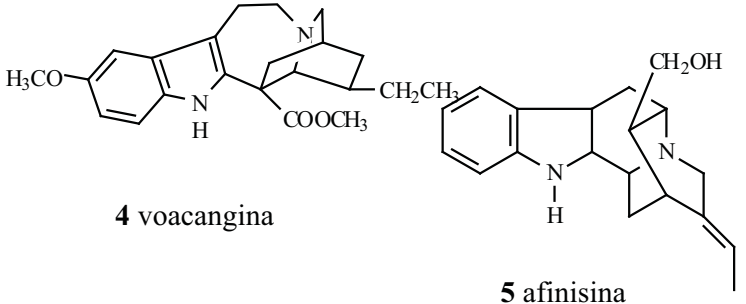<smiles>CCC1CC2CCCC(C1)C2CC</smiles>

7 ibogaína

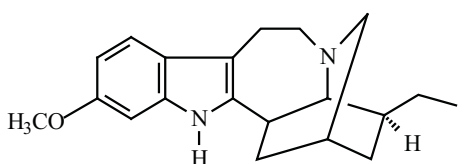

${ }_{3} \mathrm{HCOOC}^{\prime}$

9 coronaridina

8 tabernantina

Figura 1. Estruturas química de alguns alcalóides do gênero Tabernaemontana. 


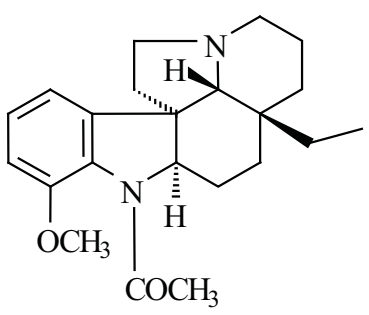

$\mathbf{1 0}$ aspidospermina<smiles>Cc1nccc2c(C)c3[nH]c4ccccc4c3cc12</smiles>

11 olivacina<smiles>COC(=O)[C@@H]1[C@H](O)CC[C@@H]2CN3CCc4c([nH]c5ccccc45)[C@@H](C[C@H]21)C3</smiles>

12 ioimbina

Figura 2. Estrutura química de alguns alcalóides do gênero Aspidosperma.

relaxante (Taesotiku et al., 1998) (Figura 1).

Dentro das espécies existentes no Brasil destaca-se a Peschiera fuchsiaefolia, recentemente reclassificada como Tabernaemontana catharinensis L. (Almeida et al., 2004) e que é popularmente conhecida pelos nomes de "leiteira", "leiteiro" ou "leiteiro de vaca", por produzir látex nas folhas, caules e frutos, com muita abundância (Correia, 1984).

Casado et al. (1984) relataram que o extrato bruto obtido das cascas dos caules de T. catharinensis apresentou atividade depressora sobre o $\mathrm{SNC}$ e provocou estimulações em útero isolado de rata. (Federici et al., 2000) também relataram que estes extratos obtidos das cascas do caule e das cascas das raízes de $T$. catharinensis apresentam uma atividade in vitro contra Plasmodium falciparum, o agente etiológico da malária. Outros trabalhos também descrevem atividades biológicas interessantes para os extratos de cascas, caules e raízes de $T$. catharinensis como, por exemplo, propriedades antiofídicas (Almeida et al., 2004; Batina et al., 2004) e antileishmania (Delorenzi et al., 2001).

Os estudos visando a micropropagação e a produção de alcalóides, bem como de outros metabólitos secundários em cultura de células, tecidos e órgãos de espécies do gênero Tabernaemontana estão sendo realizados há muitos anos (Van der Heijden et al., 1986; 1988; 1989; Sierra et al., 1991), mas estes se concentram somente em três espécies: T. pandacaqui, T. elegans e $T$. divaricata. A Tabela 1 mostra as espécies deste gênero já estudadas, os tipos de culturas empregadas e os alcalóides já identificados e a Figura 4 ilustra as estruturas individuais de cada um dos alcalóides. A espécie T. catharinensis apesar de sua importância farmacológica destacada foi alvo somente de investigações preliminares, no que se refere à produção de alcalóides ou triterpenóides em cultura de calos e células (Pereira et al., 1995; 1996). Em relação aos estudos de micropropagação com esta espécie existe somente um trabalho relacionado na literatura especializada (Oliveira et al., 2003).

Cultura de células de plantas do gênero Aspidosperma
As espécies do gênero Aspidosperma, família Apocynaceae também biossintetizam alcalóides indólicos com inúmeras aplicações farmacológicas, tais como aspidospermina (10) (diurético, hipotensivo, estimulante respiratório) (Farnsworth et al., 1973), olivacina (11) (anticancerígeno) (Guilbaud et al., 1996), ioimbina (12) (bloqueador alfa-adrenérgico). Por tratar-se de espécies silvestres produtoras de madeiras nobres de grande durabilidade, as espécies deste gênero estão sob risco de extinção. A espécie Aspidosperma ramiflorum, por exemplo, está seriamente ameaçada de extinção. Estas espécies possuem diversos compostos com interesse farmacológico, e pesquisas em nosso laboratório mostraram que a espécie possui uma marcada atividade antileishmania e antimicrobiana contra bactérias Gram positivas (Ferreira et al., 2004, Tanaka et al., 2006, Tanaka et al., 2007) (Figura 2 e 5).

A propagação tradicional das plantas do gênero Aspidosperma apresenta uma série de inconvenientes: as sementes possuem um tempo de viabilidade muito curta, o que inviabiliza a estocagem das mesmas; a produção das sementes é bi-anual ou tri-anual; a coleta de sementes das espécies é muito trabalhosa em razão do alto porte destas árvores e também porque algumas espécies possuem sementes aladas que são facilmente dispersas pelo vento.

Os primeiros trabalhos nos quais foram estabelecidos os cultivos in vitro de espécies do gênero Aspidosperma, bem como a produção de alcalóides indólicos, foram relatados por Aimi et al. (1991, 1994), Tabela 1 e Figura 3, que utilizaram o hipocótilo de plântulas jovens como fonte de explantes. Nestes trabalhos os autores descrevem à produção de alcalóides novos que não eram biossintetizados originalmente pela planta matriz. Após estes trabalhos, apenas outros três estão disponíveis na literatura recente, os realizados por Ribas et al. (2003, 2005) e o de Hubner et al. (2007) que focalizam a micropropagação em $A$. polyneuron $\mathrm{e}$ A. ramiflorum, respectivamente, e o trabalho de Oliveira et al. (2002) que descreve a produção dos alcalóides ramiflorina A (47) e ramiflorina B (48), Tabela 1 e Figura 5, em cultura de calos de $A$. ramiflorum. 
Tabela 1. Alcalóides identificados nas culturas de plantas dos gêneros Tabernaemontana e Aspidosperma.

\begin{tabular}{|c|c|}
\hline $\begin{array}{l}\text { Espécie } \\
\text { Tipo de cultura e Referência }\end{array}$ & Alcalóides Identificados \\
\hline \multicolumn{2}{|l|}{ Tabernaemontana divaricata } \\
\hline \multicolumn{2}{|l|}{ Suspensão celular } \\
\hline Van Der Heijden et al. (1988) & $\begin{array}{l}\text { vobasina }(\mathbf{3}), \text { perivina }(\mathbf{6}), \text { tabernaemontanina }(\mathbf{1 3}), \\
\text { vofilina- } \\
(1988) \text { hidroxiindolenina }(\mathbf{1 4}), 16 \text {-hidróxi-16,22- } \\
\text { desidroaparicina }(\mathbf{1 5}) \text {, aparicina }(\mathbf{1 6}) \text {, voafilina }(\mathbf{1 7}), \\
\text { valesamina }(\mathbf{1 8}) \text {, o-acetil-valesamina }(\mathbf{1 9}) \text {, tubotaivina } \\
(\mathbf{2 0}) \text {, coronaridina }(\mathbf{2 1}), 19-S \text {-heineanina }(\mathbf{2 2}), \\
\text { periciclivina }(\mathbf{2 3}) .\end{array}$ \\
\hline \multicolumn{2}{|l|}{ Tabernaemontana pandacaqui } \\
\hline \multicolumn{2}{|l|}{ Células em suspensão e calos } \\
\hline Sierra et al. (1991) & $\begin{array}{l}\text { aparicina (16), voafilina (17), 3-S-hidroxivoacangina } \\
\text { (24). }\end{array}$ \\
\hline \multicolumn{2}{|l|}{ Tabernaemontana elegans } \\
\hline \multicolumn{2}{|l|}{ Calos } \\
\hline Van Der Heijden et al. (1986) & 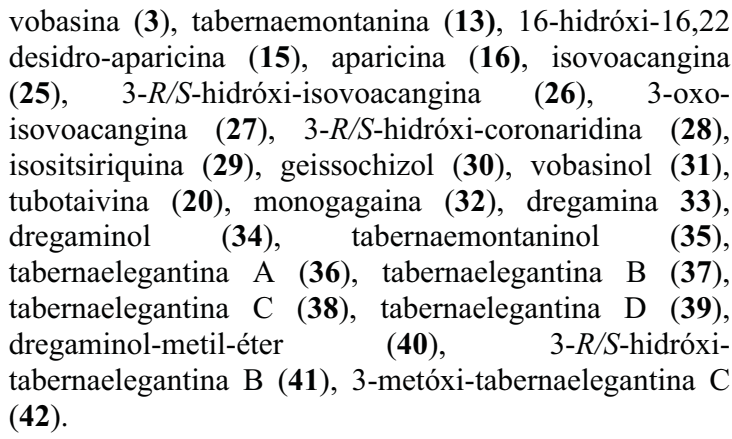 \\
\hline \multicolumn{2}{|l|}{ Tabernaemontana elegans } \\
\hline \multicolumn{2}{|l|}{ Células em suspensão } \\
\hline Van Der Heijden et al. (1989) & $\begin{array}{l}\text { vobasina }(\mathbf{3}) \text {, perivina }(\mathbf{6}) \text {, aparicina }(\mathbf{1 6}) \text {, O-acetil- } \\
\text { valesamina }(\mathbf{1 9}) \text {, tubotaivina }(\mathbf{2 0}) \text {, isositsiriquina }(\mathbf{2 9}) \text {, } \\
\text { vobasinol }(\mathbf{3 1}) \text {, triptamina }(\mathbf{4 3}) \text {. }\end{array}$ \\
\hline \multicolumn{2}{|l|}{ Aspidosperma quebracho-blanco } \\
\hline \multicolumn{2}{|l|}{ Células em suspensão } \\
\hline Aimi et al. (1991, 1994) & $\begin{array}{l}\text { aspidochibina (44), 3-oxo-14,15-desidrorhazinilam (45), } \\
\text { 11-Hidroxitubotavina (46). }\end{array}$ \\
\hline \multicolumn{2}{|l|}{ Aspidosperma ramiflorum } \\
\hline Oliveira et al. (2002) & $\begin{array}{l}\text { ramiflorina A (47), ramiflorina } B(\mathbf{4 8}) \text { e 10-metóxi- } \\
\text { geissoschizol (49). }\end{array}$ \\
\hline
\end{tabular}

\section{CONCLUSÕES}

O uso de cultura de células de planta para a produção de substâncias químicas e medicamentos contribuiu grandemente para avanços em diversas áreas da fisiologia e bioquímica vegetal. O uso de ferramentas genéticas e o grande conhecimento atual sobre a regulação das vias do metabolismo secundário poderão fornecer a base para a produção destes metabólitos em níveis aceitáveis comercialmente.

Estas evidências somadas a grande demanda atual no uso de produtos naturais com propósitos medicinais somados com as pequenas quantidades normalmente existentes nas plantas e as preocupantes implicações ambientais geradas pela coleta predatória e indiscriminada das plantas em seu ambiente natural, renovam o interesse pela utilização das tecnologias de

cultura de células de plantas.

\section{AGRADECIMENTOS}

Agradecemos a Fundação Araucária pelo financiamento do projeto envolvendo a produção de alcalóides em cultura de células, tecidos e órgãos de Tabernaemontana catharinensis e agradecemos também a CAPES.

\section{REFERÊNCIAS}

Aerts RJ, Snoeijer W, Van der Meijden E, Verpoorte R 1991. Allelopathic inhibition of seed germination by Cinchona alkaloids? Phytochemistry 30: 2947-2951.

Agra MF, França PF, Barbosa-Filho JM 2007. Synopsis of the plants known as medicinal and poisonous in Northeast of Brazil. Rev Bras Farmacogn 17: 114- 


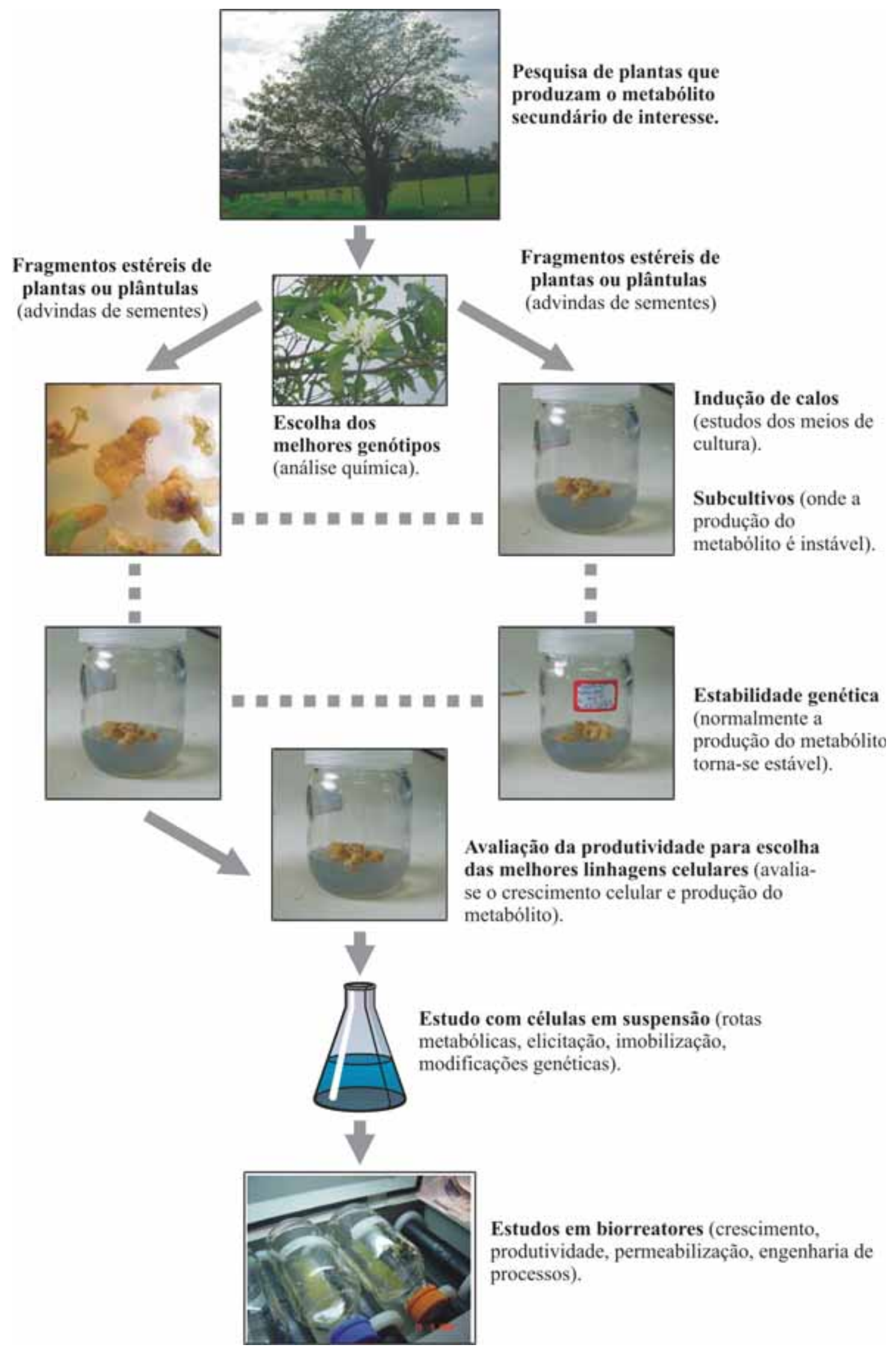

Figura 3. Estratégias gerais para produção de metabólitos secundários em cultura de células de plantas. 


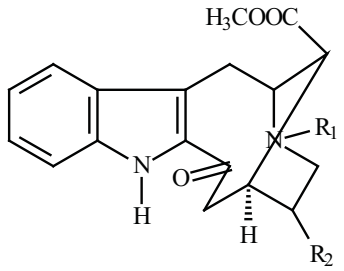

$\mathrm{R}_{1} \quad \mathrm{R}_{2}$

$13 \quad \mathrm{CH}_{3} \quad \beta-\mathrm{C}_{2} \mathrm{H}_{5}$ tabernaemontanina

$6 \mathrm{H}=\mathrm{CH}-\mathrm{CH}_{3}$ perivina

$3 \mathrm{CH}_{3}=\mathrm{CH}-\mathrm{CH}_{3}$ vobasina

$33 \quad \mathrm{CH}_{3} \quad \alpha-\mathrm{C}_{2} \mathrm{H}_{5}$ dregamina

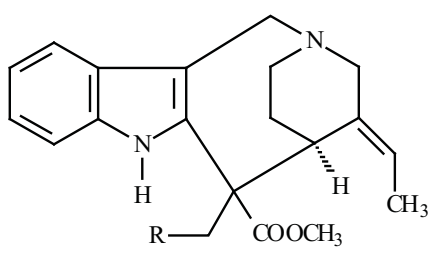

$\mathrm{R}$<smiles>CC[C@]12CCC3=Nc4ccccc4C(O)(CN(C3)CC3OC31)C2O</smiles>

14 voafilinahidroxiindolenina<smiles></smiles>

17 voafilina<smiles></smiles>

15 16-hidróxi-16, 22-desidroaparicina<smiles>C=C1C[C@@H]2CCN(C/C2=C/C)Cc2c1[nH]c1ccccc21</smiles>

16 aparicina<smiles>[2H][C@]12CCN3C[C@H]([C@@H]31)[C@]1(C)C(=C2C(C)=O)Nc2ccccc21</smiles>

20 tubotaivina

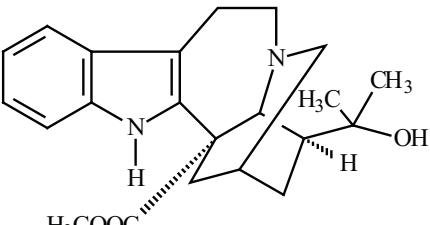

22 19-S-heineanina

$\mathrm{H}_{3} \mathrm{COO}$

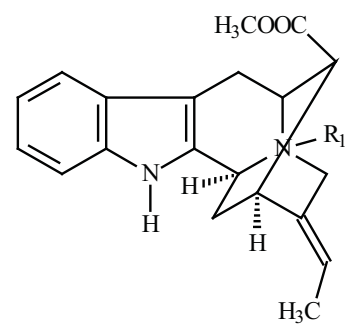<smiles>NCCc1c[nH]c2ccccc12</smiles>

23 periciclivina

Figura 4. Estruturas química dos alcalóides identificados em cultura de calos e células em suspensão de espécies do gênero Tabernaemontana. 


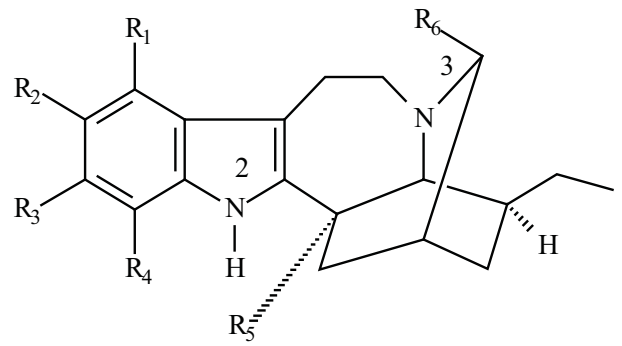

\begin{tabular}{llllllll}
\hline & $\mathrm{R}_{1}$ & $\mathrm{R}_{2}$ & $\mathrm{R}_{3}$ & $\mathrm{R}_{4}$ & $\mathrm{R}_{5}$ & $\mathrm{R}_{6}$ & \\
\hline $\mathbf{2 1}$ & $\mathrm{H}$ & $\mathrm{H}$ & $\mathrm{H}$ & $\mathrm{H}$ & $\mathrm{COOCH}_{3}$ & $\mathrm{H}$ & coronaridina \\
$\mathbf{2 5}$ & $\mathrm{H}$ & $\mathrm{H}$ & $\mathrm{H}$ & $\mathrm{H}$ & $\mathrm{COOCH}_{3}$ & $\mathrm{H}$ & isovoacangina \\
$\mathbf{2 6}$ & $\mathrm{H}$ & $\mathrm{H}$ & $\mathrm{OCH}_{3}$ & $\mathrm{H}$ & $\mathrm{COOCH}_{3}$ & $\mathrm{OH}$ & 3- $R / S$-hidróxi-isovoacangina \\
$\mathbf{2 7}$ & $\mathrm{H}$ & $\mathrm{H}$ & $\mathrm{OCH}_{3}$ & $\mathrm{H}$ & $\mathrm{COOCH}_{3}$ & $\mathrm{O}$ & 3-oxo-isovoacangina \\
$\mathbf{2 8}$ & $\mathrm{H}$ & $\mathrm{H}$ & $\mathrm{H}$ & $\mathrm{H}$ & $\mathrm{COOCH}_{3}$ & $\mathrm{OH}$ & 3- $R / S$-hidróxi-coronaridina \\
& & & & & & & \\
\hline
\end{tabular}

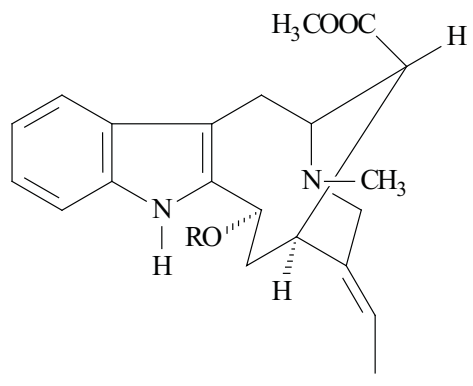

R

$34 \mathrm{H}$ dregaminol

$40 \quad \mathrm{CH}_{3}$ dregaminol-metil-éter

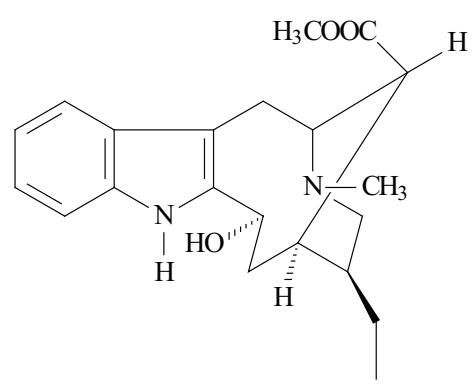

35 tabernaemontaninol

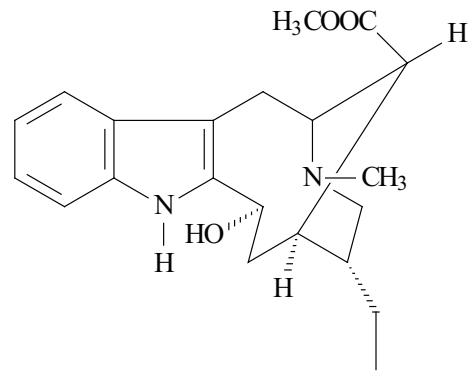

31 vobasinol

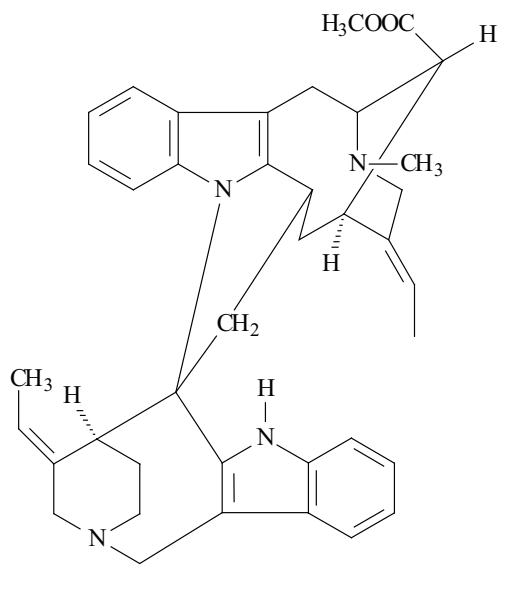

32 monogagaina

(Continuação da Figura 4) 


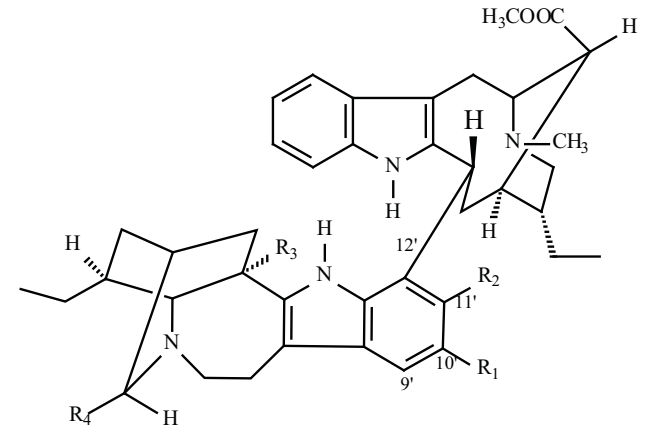
$\mathrm{R}_{1}$
$\mathrm{R}_{2}$
$\mathrm{R}_{3}$
$\mathrm{R}_{4}$

$\begin{array}{lllllll}38 & \mathrm{H} & \mathrm{OCH}_{3} & \mathrm{COOCH}_{3} & \mathrm{H} & \text { ligação em 12' } & \text { tabernaelegantina } \mathrm{C} \\ \mathbf{4 2} & \mathrm{H} & \mathrm{COOCH}_{3} & \mathrm{OCH}_{3} & \text { ligação em 12' } & \text { 3-metóxi-tabernaelegantina } \mathrm{C} \\ \mathbf{3 9} & & \mathrm{OCH}_{3} & \mathrm{COCH}_{3} & \mathrm{H} & \text { ligação em 10' } & \text { tabernaelegantina } \mathrm{D}\end{array}$

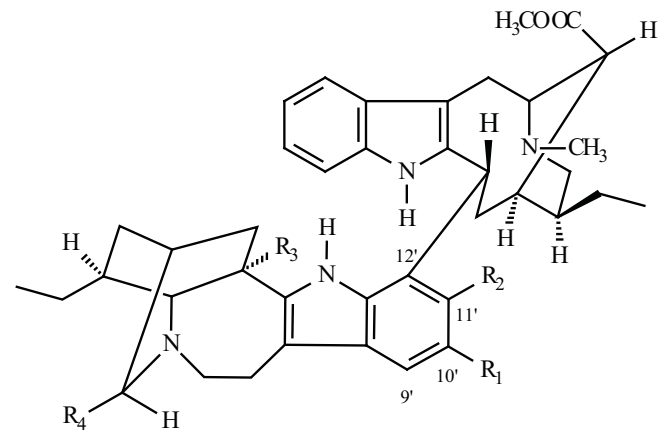
$\mathrm{R}_{1}$
$\mathrm{R}_{2}$
$\mathrm{R}_{3}$
$\mathrm{R}_{4}$

\begin{tabular}{lllllll}
\hline 36 & $\mathrm{H}$ & $\mathrm{OCH}_{3}$ & $\mathrm{COOCH}_{3}$ & $\mathrm{H}$ & ligação em 12' & tabernaelegantina A \\
$\mathbf{3 7}$ & $\mathrm{H}$ & $\mathrm{OCH}_{3}$ & $\mathrm{COOCH}_{3}$ & $\mathrm{H}$ & ligação em 10' & tabernaelegantina $\mathrm{B}$ \\
$\mathbf{3 2}$ & $\mathrm{H}$ & $\mathrm{OCH}_{3}$ & $\mathrm{COOCH}_{3}$ & $\mathrm{OH}$ & ligação em $10^{\prime}$ & $\begin{array}{l}3-R / S \text {-hidróxi- } \\
\text { tabernaelegantina B }\end{array}$
\end{tabular}

(Continuação da Figura 4) 
<smiles></smiles>

H-17

\section{$47 \quad \alpha \quad$ ramiflorina $\mathrm{A}$}

$48 \quad \beta \quad$ ramiflorina $\mathrm{B}$<smiles>[R]c1ccc2[nH]c3c(c2c1)CCN1C/C(=C/C)[C@@]([R])(C([R])([R])[R])C[C@H]31</smiles>

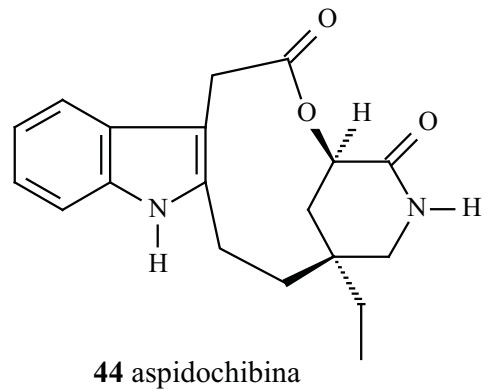<smiles>CC[C@@]1(CCC(=O)Nc2ccccc2-c2ccn3[nH]c(=O)ccc23)C=CC=CC1=O</smiles>

45 14,15-desidrorhazinilam<smiles>CCC1C2=C(C(=O)OC)[C@]3(C)CCN(C[C@H]13)c1ccc(O)cc1N2</smiles>

46 11-hidroxi-tubotaivina

\begin{tabular}{lllll}
29 & $\mathrm{H}$ & $\mathrm{CH}_{2} \mathrm{OH}$ & $\mathrm{CO}_{2} \mathrm{CH}_{3}$ & isositsiriquina \\
30 & $\mathrm{H}$ & $\mathrm{H}$ & $\mathrm{CH}_{2} \mathrm{OH}$ & geissoschizol \\
49 & $\mathrm{OCH}_{3}$ & $\mathrm{CH}_{2} \mathrm{OH}$ & $\mathrm{H}$ & 10-metóxi-geissoschizol \\
\hline
\end{tabular}

Figura 5. Estruturas química dos alcalóides identificados em cultura de calos e células em suspensão de espécies do gênero Aspidosperma. 
140.

Agra MF, Silva KN, Basílio IJLD, França PF, Barbosa-Filho JM 2008. Survey of medicinal plants used in the region Northeast of Brazil. Rev Bras Farmacogn 18: 472-508.

Aimi N, Uchida N, Ohya N, Hosokawa H, Takayama H, Sakai S 1991. Novel indole alkaloids from cell suspension cultures of Aspidosperma quebracho blanco Schlecht. Tetrahedron Lett. 32: 4949-4952.

Aimi N, Stöckigt J, Uchida N, Ohya N, Hosokawa H, Takayama H, Sakai S, Mendoza L, Obitz P 1994. Isolation of two nitrogenous metabolites from the cultured cells of Aspidosperma quebracho-blanco. Heterocycles 38: 2411-2414

Almeida L, Cintra ACO, Veronese ELG, Nomizo A, Franco JJ, Arantes EC, Giglio JR, Sampaio S V 2004. Anticrotalic and antitumoral activities of gel filtration fractions of aqueous extract from Tabernaemontana catharinensis (Apocynaceae). Comp Biochem Physiol Part C 137: 19-27.

Amaral FMM, Ribeiro MNS, Barbosa-Filho JM, Reis AS, Nascimento FRF, Macedo RO 2006. Plants and chemical constituents with giardicidal activity. Rev Bras Farmacogn 16 (Supl.): 696-720.

Barbosa-Filho JM, Nascimento-Júnior FA, Tomaz ACA, Athayde-Filho PF, Silva MS, Cunha EVL, Souza MFV, Batista LM, Diniz MFFM 2007. Natural products with antileprotic activity. Rev Bras Farmacogn 17: 141-148.

Barbosa-Filho JM, Alencar AA, Nunes XP, Tomaz ACA Sena-Filho JG, Athayde-Filho PF, Silva MS, Souza MFV, da-Cunha EVL 2008. Sources of alpha-, beta, gamma-, delta- and epsilon-carotenes: A twentieth century review. Rev Bras Farmacogn 18: 135-154.

Barreiro E 1991. A Importância da Síntese de Fármacos na Produção de Medicamentos. Quim Nova 14: 179188.

Barros Neto B, Scarmino IS, Bruns RE 1996. Planejamento e otimização de experimentos. Campinas- SP: Editora da Unicamp, p. 62-63.

Batina MFC, Cintra ACO, Giglio JR, Pereira OS, Dias DA, França SC, Sampaio SV 2004. Inhibition of the lethal and myotoxic activities of Crotalus durissus terrificus venom by Tabernaemontana catharinensis A. DC. (Apocynaceae). Planta Med 66: 424-428.

Berlin J, Sasse F 1985. Selection and screening techniques for plant cell cultures. Adv Biochem Eng Biot 31: 99132.

Biavatti M, Marensi V, Leite SN, Reis A 2007. Ethnopharmacognostic survey on botanical compendia for potential cosmeceutic species from Atlantic Forest. Rev Bras Farmacogn 17: 640-653.

Bourgaud F, Gravot A, Milesi S, Gontier E 2001. Production of plant secondary metabolites: a historical perspective. Plant Sci161: 839-851.

Box GEP 1954. The exploration and exploitation of response surfaces: some general considerations and examples. Biometrics 10: 16-60.

Casado MMCW, Silva OE, Henriques AT, Mariz G, Wandscheer DE, Silva NH 1984. Rev Inst Antibióticos 22: 11.

Charlet S, Gillet F, Villarreal ML, Barbotin JN, Fliniaux MA, Nava-Sucedo E 2000. Immobilisation of Solanum chrysotrichum plant cells withi Ca-alginate gel beads to produce an antimycotic spirostanol saponin. Plant Physiol Biochem 38: 875-870.

Choi YH, Yoo KP, Kim J 2002. Supercritical fluid extraction and liquid chromatography-electrospray mass analysis of vinblastine from Catharanthus roseus. Chem Pharm Bull 50: 1294-1296.

Collin HA 2001. Secondary product formation in plant tissue cultures. Plant Growth Regul 34: 119-134.

Cordell GA 1981. Introduction to alkaloids: A Biogenetic approach. Nova York: John-Wiley \& Sons, p. 208.

Correia MP 1984. Dicionário das plantas úteis do Brasil e das exóticas cultivadas. Brasília: Ministério da Agricultura.

Croteau R, Kutchan TM, Lewis NG 2000, Natural Products (Secondary Metabolites). In: Buchanan B., Gruissem W., Jones R. (Eds.) Biochemistry \& Molecular Biology of Plants, Rockville: American Society of Plant Physiologists, p.1250-1318.

Dagnino D, Schripsema J, Peltenburg A, Verpoorte R 1991. Capillary gas chromatography of indole alkaloids: investigation of the alkaloids present in the Tabernaemontana divaricata cell suspension culture. J Nat Prod 54: 1558-1563.

Delorenzi JC, Attias M, Gattass CR, Andrade M, Rezende C, Pinto AC, Henriques AT, Bou-Habib DC, Saraiva EMB 2001. Antileishmanial activity of an indole alkaloid from Peschiera australis. Antimicrob Agents Chemother 45: 1349-1354.

Dixon AR, Gonzales RA 1994. Plant cell culture: A pratical approach. New York: Oxford University Press.

Dong HD, Zhong JJ 2001. Significant improvement of taxane production in suspension cultures of Taxus chinensis by combining elicitation with sucrose feed. Biochem Eng $J$ 8: 145-150.

Farnsworth NR, Lyon RL, Fong HHS, Svoboda GH 1973. Biological and phytochemical evaluation of Plants $\mathrm{XI}$ : Isolation of aspidospermine, quebrachidine, rhazinilam (-)-pyrifolidine, and akuammidine from Aspidosperma quebracho-blanco (Apocynaceae). $J$ Pharm Sci 62: 218-221.

Federici E, Palazzino G, Nicoletti M, Galeffi C 2000 Antiplamodial activity of the alkaloids of Peschiera fuchsiaefolia. Planta Med 66: 93.

Ferreira ICP, Leon LL, Gobbi Filho L, Lonardoni MVC, Silveira TGV, Machado GMC, Oliveira AJB 2004. Antileishmanial activity of alkaloidal extract from Aspidosperma ramiflorum. Mem Inst Oswaldo Cruz 99: $325-327$

Funke I, Melzig MF 2006. Traditionally used plants in diabetes therapy - phytotherapeutics as inhibitors of $\alpha$-amylase activity. Rev Bras Farmacogn 16: 1-5.

Giroud C, Van Der Leer T, Van Der Heijden R, Verpoorte R, Heeremans CEM, Nierssen WMA, Van Der Greef J 1991. Termospray liquid chromatography/mass spectrometry (TSP LC/MS) analysis of the alkaloids from Chinchona in vitro cultures. Planta Med 57: 142-148.

Guilbaud N, Kraus-Berthier L, Saint-Dizier D, Rouillon MH, Jan M, Burbridge M, Visalli M, Bisagni E, Pierre A, Atassi G 1996. In vivo antitumor activity of S 16020 2 a new olivacine derivative. Cancer Chemoth Pharmacol 38: 513-521.

Gutman A, Khandurina J, Budworth P, Wenying X, Hou YM, 
Wang X 2004. Analysis of combinatorial natural products by HPLC and CE. PharmaGenomics 3242.

Hamburger M, Hostettmann K 1991. Bioactivity in plants: between phytochemistry and medicine. Phytochemistry 30: 3864-3874.

Harborne JB 1988. Introduction to Ecological Biochemistry. London: Academic Press.

Harborne JB 1998. Phytochemical Methods. London: Chapman $\&$ Hall.

Harborne JB 1999. Classes and functions of secondary products, In: Walton NJ, Brown DE (Ed.). Chemicals from plants, perspectives on secondary plant products. London: Imperial College, p.1-25.

Hu WW, Yao HU, Zhong J J 2001. Improvement of Panax notoginseng cell cultures for production of ginseng saponin and polysaccharide by high-density cultivation of pneumatically agitated bioreactors. Biotechnol Prog 17: 838-846.

Hubner HI, SilvaLV, Capatti I, Fumagali E, Souto ER, Gonçalves RAC, Oliveira AJB 2007. Multiplicação in vitro de Aspidosperma ramiflorum Muell. Arg. (Apocynaceae). Acta Sci Health Sci 29: 63-66.

Hulst AC, Tramper J, Brodelius P, Eijkenboom LJC, Lyben KCA 1985. Immobilized plant cells: respiration and oxygen transfer. J Chem Technol Biot 35: 198-204.

Jones A, Veliky AI 1981. Effect of medium constituents on the viability of immobilized plant cells. Can J Bot 39: 511-521.

Kossel A 1891. Über die chemische zusammensetzung der zelle. Archiv für Physiologie 181-186.

Krikorian AD, Steward FC 1969. Biochemical differentiation: the biosynthetic potentialities of growing and quiescent tissue. In: Steward FC (Ed.) Plant physiology, a treatise. Lancaster: Academic Press, p.227-326.

Lee CWT, Shuler ML 2000. The effect of inoculum density and conditioned medium on the production of ajmalcine and catharanthine from immobilized Catharanthus roseus cells. Biotechnol Bioeng 67: 61-71.

Lépine F, Milot S, Zamir L, Morel R 2002. Liquid chromatographic/mass spectrometric determination of biologically active alkaloids in extracts os Peschiera fuchsiaefolia. J Mass Spectrom 37: 216222.

Li J, Ou-Lee TM, Raba R, Amundson RG, Last RL 1993. Arabidopsis mutants are hypersensitive to UV-B radiation. Plant Cell 5: 171-179.

Machado MFPS, Colleti SAO 1991. Expressão gênica no desenvolvimento de tecidos vegetais in vitro. Maringá: Editora da Universidade Estadual de Maringá, 95p.

Machado FAPSA, Capelasso M, Oliveira AJB, Zamuner MLM, Mangolin CA, Machado MFPS 2006. Alkaloid production and Isozymes expression from cell suspension culture of Cereus peruvianus Mill (Cactaceae). J Plant Sci 1: 324-331.

Mazak K, Szakacs A, Nemes A, Noszal B 2000. Capillary electrophoresis separation of vinpocetine and related compounds: prediction of electrophoretic mobilities in partly aqueous media. Electrophoresis 21: 24172423.

Oliveira AJB, Koike L, Shepherd SKL, Reis FAM 2002. Callus culture of Aspidosperma ramiflorum Muell. Arg.: growth and alkaloid production. Acta Scientiarum 23: 609-612.

Oliveira AJB, Machado MFPS, Ferreira A, Sato FY, CarvalhoVM 2003. In vitro multiplication of Tabernaemontana fuchsiaefolia L. (Apocynaceae). Rev Árvore 27: 421-425.

Pereira PS, Dias DA, França SC 1995. Alcalóides em cultura de calos de Peschiera fuchsiaefolia. XIV Simpósio de Plantas Medicinais do Brasil. Florianópolis, Brasil.

Pereira OS, Dias DA, França SC 1996. Tissue culture of Peschierafuchsiaefolia.II Encontro Latinoamericano de Biotecnologia Vegetal - REDBIO. Puerto Iguazu, Argentina.

Ribas LLF, Zanette F, Kulchetscki L, Guerra MP 2003. Establishment of aseptic cultures of Aspidosperma polyneuron. Cienc Florestal 13: 115-122.

Ribas LLF, Zanette F, Kulchetscki L, Guerra MP 2005. Micropropagação de Aspidosperma polyneuron (Peroba-Rosa) a partir de segmentos nodais de mudas juvenis, Rev Árvore 29: 517-524

Santos AS, Araújo SF, Goulart HF, Caetano LC, Arruda MSP, Santos LS, Santa'Ana AEG 2007. A dehydrorotenoid produced by callus tissue culture and wild plant roots of Boerhaavia coccinea. Rev Bras Farmacogn 17: 538-541.

Saúde-Guimarães DA, Faria AR 2007. Substâncias da natureza com atividade anti-Trypanosoma cruzi. Rev Bras Farmacogn 17: 455-465.

Scott AI, Lee, SL, Culver MG, Wan W, Hirata T, Guéritte F, Baxter RL, Nordlöv H, Dorschell A, Mizokami H, Mackenzie NE 1981. Biosynthesis of indole alkaloids. Heterocycles 15: 1257-1274.

Shepherd SLK 1995. O jardim secreto das plantas. Cienc Hoje 19: 59-62.

Sierra MI, Van Der Heijden R, Schripsema J, Verpoorte R 1991. Alkaloid production in relation to differentiation in cell and tissue cultures of Tabernaemontana pandacaqui. Planta Med 57: 543-547.

Silvestrini A, Pasqua G, Botta B, Monacelli B, van der Heijden R, Verpoorte R 2002. Effect of alkaloid precursor feeding on a Camptotheca acuminata cell line. Plant Physiol Biochem 40: 749-753.

Steward N, Martin R, Engasser JM, Goergen JL 1999. A new methodology for plant cell viability assessment using intracellular esterase activity. Plant Cell Rep 19: 171-176.

Taesotikul T, Panthong A, Kanjanapothi D, Verpoorte R, Scheffer JJC 1998. Cardiovascular activity of the crude alkaloidal fraction from Tabernaemontana pandacaqui in the rat. $J$ Ethnopharmacol 59: 131137.

Tanaka JCA, Silva CC, Dias Filho BP, Nakamura CV, Oliveira AJB 2006. Antibacterial activity of indole alkaloids from Aspidosperma ramiflorum. Braz J Med Biol Res 39: 387-391.

Tanaka JCA, Silva CC, Ferreira ICP, Machado GMC, Leon LL, Oliveira AJB 2007. Antileishmanial activity of indole alkaloids from Aspidosperma ramiflorum. Phytomedicine 14: 377-380.

Theodorides G, Jong CF, Laskaris G, Verpoorte R 1998. Application of SPE for the HPLC analysis of taxanes from Taxus cell cultures. Chromatographia 47: 2534. 
Van Beek TA, Verpoorte R, Baerheim Svendensen A, Leeuwewberger AMJ, Bisset NG 1984. Tabernaemontana L. (Apocynaceae): A review of its taxonomy, phytochemistry, ethnobotany and pharmacology. J Ethnopharmacol 10: 1-156.

Van Beek TA, Van Gessel MAJT 1988. Alkaloids: chemical and biological perspectives. In: Pelletier SW (Ed.) Alkaloids: Chemical and Biological Perspectives. New York: John Wiley, p. 75.

Van der Heijden R, Brouwer RL, Verpoorte R, Wijnsma R, Van Beek TA, Harkes PAA, Baerheim SA 1986. Indole alkaloids from a callus culture of Tabernaemontana elegans. Phytochemistry 25: 843-846.

Van der Heijden R, Lokkerbol HA, Kool LPJ, Lamping PJ, Harkes PAA, Verpoorte R 1988. Accumulation of indole alkaloids in a suspension culture of Tabernaemontana divaricata. Planta Med 54: 393397.

Van Der Heijden R, Louwe LC, Verhey ER, Harkes PAA, Verpoorte R 1989. Characterization of a suspension culture of Tabernaemontana elegans on growth, nutrient uptake, and accumulation of indole alkaloids. Planta Med 55: 158-162.

Verpoorte R, Maraschi M 2001. Engenharia do metabolismo de plantas medicinais. In: Yunes R. A., Calixto J.B. (org.) Plantas medicinais sob a ótica da química medicinal moderna. Chapecó, Brasil: Argos, p.381432.

Viegas Jr C, Bolzani C, Silva V, Eliezer J 2006. Os produtos naturais e a química medicinal moderna. Quim Nova 29: 326-337.

Villareal ML, Arias C, Vega J, Feria-Velasco A, Ramirez OT, Nicasio P, Rojas G, Quintero R 1997. Cell suspension culture of Solanum chrysotrichum - a plant producing an antifungal spirostanol saponin. Plant Cell Tiss Org Cult 50: 39-44.

Wang ZY, Zhong JJ 2002. Combination of conditioned medium and elicitation enhances taxoid production in bioreactor cultures of Taxus chinenesis cells. Biochem Eng J 12: 93-97.

Weisback JA, Raffauf RF, Ribeiro O, Macko E, Douglas BJ 1963. Problems in the chemotaxonomy I. Alkaloids of Peschiera affinis. J Pharm Sci 52: 350.

Yamada Y, Sato F 1981. Production of berberine in cultured cells of Coptis japonica. Phytochemistry 20: 545547.

Yamada Y, Fugita Y 1983. Production of useful compounds in culture. In: Evan DA, Sharp, Ammirado PV, Yamada Y (Eds.) Handbook of Plant Cell Culture. New York: Publishing Co., pp. 717-28.

Yunes RA, Cechinel Filho V 2001. Breve análise histórica da química de plantas medicinais: Sua importância na atual concepção de fármaco segundo os paradigmas ocidental e oriental. In: Yunes R. A., Calixto J.B. (org.) Plantas medicinais sob à ótica da química medicinal moderna. Chapecó, Brasil: Argos, p. 1844.

Zocoller M, Oliveira AJB, Saragiotto MH, Grzesiuk VL, Vidotti GJ 2005. Qualitative determination of indole alkaloids of Tabernaemontana fuchsiaefolia (Apocynaceae). J Braz Chem Soc 16: 1372-1377. 